\title{
Sinopse do gênero Ancylocera Audinet-Serville (Coleoptera, Cerambycidae, Trachyderini) ${ }^{1}$
}

\author{
Marcela L. Monné ${ }^{2}$ \\ Dilma Solange Napp ${ }^{2}$
}

\begin{abstract}
Synopsis of the genus Ancylocera Audinet-Serville (Coleoptera, Cerambycidae, Trachyderini). A synopsis of the genus Ancylocera Audinet-Serville, 1834 is presented. The genus is redescribed, with description of two new species, Ancylocera. sergioi sp. n., from Brazil and A. spinula sp. n., from Colômbia, and a key to the species is provided. All the species (except $A$. cardinalis) are illustrated and comments on their hosts and distribution are given.

KEY WORDS. Ancylocera, Ancylocerina, Cerambycinae, synopsis, taxonomy
\end{abstract}

MONNÉ (1994) e MONNÉ \& GIESBERT (1995) arrolaram 11 espécies em Ancylocera Audinet-Serville, 1834, com distribuição desde o sul dos Estados Unidos até a Argentina. Recentemente, NAPP \& MONNÉ (2001) propuseram o gênero Assycuera para incluir quatro espécies descritas em Ancylocera (A. macrotela Bates, 1792, A. rubella Bates, 1880, e A. scabricollis Chemsak, 1963 do México e $A$. waterhousei White, 1855 do norte do Brasil). Das sete espécies que permaneceram no gênero, seis foram descritas da Região Neotropical (América do Sul e México) e apenas uma da Região Neártica (Estados Unidos).

Nesta contribuição, duas novas espécies são acrescidas ao gênero: Ancylocera sergioi $\mathbf{s p .} \mathbf{n}$. do Brasil, e A. spinula sp. n. da Colômbia. Ancylocera sallei Buquet, 1857, conhecida apenas da descrição original, é redescrita. As demais espécies foram descritas ou redescritas em publicações recentes (CHEMSAK 1963; LINSLEY 1964; VIANA 1971). A minuciosa redescrição de Ancylocera feita por VIANA (1971) aliada à caracterização de Ancylocerina Thomson, 1864, por MonNÉ \& NAPP (2000b), permite que o gênero seja sucintamente redescrito.

$\mathrm{O}$ material estudado pertence às seguintes instituições: (CASC) California Academy of Sciences, Califórnia; (DZUP) Coleção de Entomologia Pe J.S. Moure, Departamento de Zoologia, Universidade Federal do Paraná, Curitiba; (MNHN) Muséum National d'Histoire Naturelle, Paris; (MNRJ) Museu Nacional, Universidade Federal do Rio de Janeiro, Rio de Janeiro; (MZSP) Museu de Zoologia, Universidade de São Paulo, São Paulo.

Considerando a publicação de um catálogo (MonNÉ 1994), as citações bibliográficas mencionadas em cada táxon restringem-se à descrição original e à citação de MONNÉ (1994). Quando pertinente, outras citações são acrescidas.

1) Contribuição número 1249 do Departamento de Zoologia, Universidade Federal do Paraná.

2) Departamento de Zoologia, Universidade Federal do Paraná. Caixa Postal 19020, 81531-990 Curitiba, Paraná, Brasil. Bolsista do CNPq e CAPES. 


\section{Ancylocera Audinet-Serville, 1834}

Ancylocera Audinet-Serville, 1834: 107; Monné, 1994: 17; Monné \& Giesbert, 1995: 141; Monné \& Napp, 2000: 351, 355; Napp \& Monné, 2001.

Espécie-tipo: Cerambyx ? cardinalis Dalman, 1823 (designação de Thomson, 1864: 212).

Dorso da cabeça com pontos grossos e densos. Fronte microcorrugada e hirsuta. Tubérculos anteníferos acuminados. Lobos oculares inferiores pouco proeminentes; os superiores com largura pouco maior que 1/3 da largura dos inferiores, bem afastados entre si no vértice; ligação entre os lobos tão larga quanto o lobo superior. Genas subtriangulares, subparalelas, no máximo, com metade do diâmetro do lobo ocular inferior. Mandíbulas rugoso-pontuadas, sem lobo globoso dorsal. Antenas com evidente dimorfismo sexual; nos machos ultrapassam os ápices elitrais em pelo menos três antenômeros; nas fêmeas alcançam o 1/3 basal ou a metade dos élitros. Machos: escapo robusto, algo inflado, sensivelmente alargado na base e esta com projeções laterais interna e externa; pedicelo com conspícua projeção láteroexterna; antenômeros III-IV evidentemente deprimidos, com comprimentos subiguais ou o III cerca de 1/3 mais longo, sempre mais curtos que o V; V-X cilíndricos, mais evidente os VI-X, expandidos somente no ápice externo; V-VIII com comprimentos crescentes, os VII-VIII cerca de duas vezes mais longos que o III; IX-X decrescentes; XI fortemente reduzido e em forma de gancho; sistema porífero restrito aos ápices ventral e dorsal externos dos antenômeros, usualmente reduzido nos III-IV. Fêmeas: escapo menos robusto, tão largo na base quanto no ápice, sem projeções látero-basais; pedicelo com projeção externa menos evidente; antenômeros III-X curtos, serreados e subiguais em comprimento; XI fortemente afilado no ápice, tão ou pouco mais longo que o X; sistema porifero reduzido ou ausente no ápice dorsal dos antenômeros III-IV, bem desenvolvido na metade apical do V, nos 2/3 apicais do VI e ao longo de toda a face lateral externa nos VII-XI. Protórax cilíndrico, paralelo a subarredondado aos lados, com cerca da metade do comprimento dos élitros. Pronoto subplano, densamente pontuado, com ou sem estrias transversais. Machos com pontuação sexual nos terços anterior e posterior do pronoto, lados do protórax e no prosterno, exceto em estreita faixa mediana lisa. Metasterno com pontos grossos e esparsos. Élitros cerca de 2,5 a três vezes a largura umeral, grossa e densamente pontuados, os pontos alinhados em fileiras longitudinais (em A. bruchi Viana, 1971 com pontos menores, mais densos e pouco alinhados). Ápices abruptamente declives, truncados e não projetados além do ápice do abdome; ângulo sutural elevado. Pernas com superfície brilhante e subglabras. Fêmures pedunculados, abruptamente clavados. Mesofêmures com espinho ou aguçados no ápice interno. Metafêmures com espinho apical interno desenvolvido, alcançam ou apenas ultrapassam os ápices elitrais. Metatarsômero I tão longo ou pouco mais curto que os dois seguintes reunidos. Urosternito V com margem apical sinuosa nos machos e arredondada nas fềmeas.

Discussão. O gênero Ancylocera é muito semelhante a Assycuera Napp \& Monné, 2001 e distingue-se principalmente pelos fêmures abruptamente clavados e pelas antenas dos machos com o escapo fortemente alargado na base, o pedicelo com evidente projeção lateral externa, os antenômeros VI-X cilíndricos e expandi- 
dos somente no ápice e o XI fortemente reduzido e em forma de gancho. Em Assycuera, os fềmures são gradualmente clavados ou lineares, o escapo é desprovido de projeções laterais e tão largo na base quanto no ápice, o pedicelo não é projetado externamente, os antenômeros V-X são subserreados e o XI é cilíndrico-alongado. Dos demais gêneros de Ancylocerina, Ancylocera distingue-se pela combinação dos seguintes caracteres aliados aos citados acima: mandíbulas, nos dois sexos, sem lobo globoso dorso-basal; antenômero III nitidamente mais curto que os $\mathrm{V}$ a X; protórax cilíndrico alongado, o pronoto sem gibosidades e élitros não projetados além do ápice do abdome.

As espécies que compõem o gênero Ancylocera são muito uniformes morfologicamente e distinguem-se principalmente pela pontuação do protórax e pelo colorido do corpo.

\section{Chave para as espécies de Ancylocera}

1. Élitros com faixa enegrecida basal, sutural ou apical ................ 2

-Élitros unicolores . . . . . . . . . . . . . . . . . . . . . . . . 5

2(1). Élitros com 1/3 apical pretos (cabeça, antenas e protórax pretos ou castanhoescuros, contrastantes com os $2 / 3$ basais dos élitros alaranjados; antenômeros $\mathrm{V}$-X fortemente deprimidos, expandidos desde a base e com aspecto quadrangular; V visivelmente mais longo que III e IV; mesofêmures com espinho apical interno desenvolvido) (Fig. 1). BRASIL (Pará, Mato Grosso, Rondônia) ................................. sergioi $\mathbf{s p .} \mathbf{n}$.

-Élitros com faixa basal ou sutural enegrecida .................. 3

3(2). Élitros com faixa basal castanho-escura; superfície com pontos finos, densos e não alinhados; abdome com pontuação pouco aparente (Figs 3, 13). ARgentina (Córdoba, Santiago del Estero, Tucumán) .............. ................................... Aruchi Viana, 1971

- Élitros com faixa enegrecida ao longo da sutura, com pontos grossos e alinhados em toda a superfície; abdome com pontos finos, mais adensados e evidentes

4(3). Macho: pronoto com estrias transversais em quase toda a superfície, a pontuação sexual pouco aparente nos terços anterior e posterior. Lados do protórax com pontos grossos, densos e pontuação sexual pouco aparente. Base do escapo sem rugas longitudinais (Fig. 8). MÉXICO (Yucatán) ...... A. sallei Buquet, 1857

- Macho: pronoto com estrias transversais pouco aparentes em estreita faixa transversal mediana. Todo o protórax com densa pontuação sexual, aspecto opaco, entremeada com pontos finos, rasos, pouco aparentes. Base do escapo com rugas longitudinais (Figs 4, 12). PANAMÁ (Bajo Colorado), COLÔMBIA (La Garita) ........................ A. nigella Gounelle, 1913

5(1). Meso- e metafêmures com espinhos apicais internos bem desenvolvidos; nos mesofêmures com comprimento subigual à largura apical do mesofêmur; nos metafêmures cerca de 1,5 vezes a largura apical do metafềmur. Protórax 
com pêlos longos e abundantes (pronoto com faixa anterior e a margem posterior pretas; cabeça preta acastanhada) (Fig. 2). CoLÔMBIA (Valle del Cauca) ................................... A. spinula $\mathbf{s p . ~} \mathbf{n}$.

- Mesofêmures, no máximo, com curto espinho apical interno; espinho dos metafêmures mais curtos que a largura apical dos metafêmures; protórax com pilosidade curta e pouco aparente . . . . . . . . . . . . . . . 6

6(5). Lados do protórax, nos três quartos posteriores, vermelho-alaranjados; pronoto castanho-escuro com áreas ou faixa mediana com áreas avermelhadas . . . 7

- Lados do protórax concolores com o pronoto ................. 8

7(6). Macho: pronoto com faixa centro-longitudinal vermelha e estrias transversais em toda a superfície, mais grossas e marcadas no terço mediano; terços anterior e posterior com pontos grossos, profundos, a pontuação sexual pouco aparente (Fig. 8). MÉXICO (Yucatán) ........ A. sallei Buquet, 1857

- Macho: pronoto com áreas avermelhadas nos terços anterior e posterior e estrias finas restritas ao terço mediano; terços anterior e posterior com pontuação sexual densa, entremeada com pontos finos, rasos e esparsos (Figs 7, 11). MÉxico (Chiapas), Honduras (Comayagua) . . . . . . . . . . . . . . .

A. amplicornis Chemsak, 1963

8(6). Macho: pronoto com estrias transversais pouco aparentes em estreita faixa mediana. Todo o protórax com densa pontuação sexual, aspecto opaco, entremeada com pontos finos, rasos e pouco aparentes (Figs 4, 12). PANAMÁ (Bajo Colorado), ColômBIA (La Garita) ........ A. nigella Gounelle, 1913

- Macho: pronoto, no terço mediano, com estrias e pontos evidentes, a pontuação sexual restrita aos terços anterior e posterior, aspecto brilhante. Lados do protórax e prosterno com pontos moderadamente grossos e densos, a pontuação sexual pouco aparente . ........................ 9

9(8). Cabeça, pronoto e esternos torácicos pretos a castanho-avermelhados, contrastantes com os élitros e abdome, alaranjados (Fig. 5). EsTADOS Unidos (Carolina do Norte, Flórida ao Texas) ......... A. bicolor (Olivier, 1795)

- Cabeça, pronoto, meso- e metasterno, élitros e abdome concolores, vermelhos ou alaranjados .............................. 10

10(9). Prosterno com larga faixa mediana escura, restante do protórax vermelho ou alaranjado (Fig. 10). Base do escapo sem estrias longitudinais. Macho: centro do pronoto com rugas transversais evidentes; terços anterior e posterior sem rugas, com pontuação sexual evidente entremeada com pontos esparsos. Fêmea: pronoto e lados do protórax finamente estriados em toda superfície, com pontos pouco conspícuos (Figs 6, 9) MÉxICO (Jalisco, Morelos, Oaxaca) ................ A. michelbacheri Chemsak, 1963

- Prosterno vermelho, concolor com os lados do protórax e pronoto. Base do escapo com estrias longitudinais. Pronoto, em ambos os sexos, pontuado-rugoso em toda a superfície. Macho: pontuação sexual pouco conspícua. BRAsIL (Goiás, Paraíba ao Rio Grande do Sul), Paraguai, Argentina, Uruguai .... . A. cardinalis (Dalman, 1823) 


\section{Ancylocera sergioi sp. $\mathbf{n}$.}

Fig. 1

Fêmea. Tegumento de maneira geral preto a castanho-avermelhado; antenômeros distais e pedúnculo dos fêmures mais claros; $3 / 4$ basais dos élitros, escutelo e abdome vermelho-alaranjados. Dorso da cabeça com pontos microesculturados, profundos e confluentes, aspecto escabroso. Genas com pontos finos, rasos e densos. Antenas alcançam o meio dos élitros; escapo com pontos grossos e densos e com estrias longitudinais na base; antenômeros III-XI impontuados, subglabros e microesculturados; V-X expandidos desde a base e com aspecto quadrangular; III tão longo quanto IV e cerca de $1 / 3$ mais curto que o V; V-VII subiguais; VIII-X decrescescentes; XI 1/3 mais longo que o X.; sistema porífero ausente na face dorsal dos antenômeros III-IV. Protórax cerca de 1,5 vezes mais longo que largo, evidentemente cilíndrico, com lados subparalelos; pilosidade curta, ereta, esparsa e esbranquiçada. Pronoto plano, com estrias transversais e pontos microesculturados, grossos, moderadamente densos, exceto no disco. Lados do protórax conspicuamente estriados. Prosterno com pontos grossos e esparsos. Mesepisterno e mesepimero com superfície microesculturada e irregularmente pontuados. Mesosterno com pontos grossos e esparsos. Metasterno com pontos muito grossos e microesculturados. Escutelo glabro, subtriangular, deprimido no meio e com superfície microesculturada. Élitros cerca de 2,5 vezes mais longos que largos, com pontos grossos, densos, profundos e alinhados em fileiras e pontos menores e mais próximos entre si ao longo da sutura e no terço apical. Espinho apical dos mesofêmures com cerca de $2 / 3$ da largura apical do mesofêmur. Metafêmures apenas alcançam o ápice elitral, o espinho apical interno subigual à largura apical do metafêmur. Metatarsômero I mais curto que os dois seguintes reunidos. Urosternitos subglabros. Urosternito I com pontos grossos mais adensados no meio; os seguintes com pontos finos e esparsos.

Dimensões, em mm, fêmea. Comprimento total, 11,8-9,0; comprimento do protórax, 3,5-2,8; largura do protórax, 2,2-1,6; comprimento do élitro, 6,8-5,3; largura umeral, 2,5-1,8.

Material-tipo. Holótipo fêmea, BRAsıL, Mato Grosso: Sinop, XI.1976, Roppa \& Alvarenga leg. (MNRJ). Parátipos. Pará: Óbidos, 1 fêmea, VIII.1959, F.M. Oliveira leg. (MNRJ); Tucuruí, I fềmea, I. 1980, B. Silva leg. (MNRJ); Santarém, 1 fêmea (MZSP). Rondônia: Ariquemes, 1 fềmea, VIII.1978, B. Silva leg. (DZUP).

Variabilidade. O parátipo fêmea de Santarém (Pará) apresenta o pronoto com pontos grossos e densos e estrias transversais evidentes apenas aos lados do protórax.

Discussão. Ancylocera sergioi distingue-se prontamente das demais espécies de Ancylocera pela combinação dos seguintes caracteres: élitros com terço apical enegrecido; protórax evidentemente cilíndrico, apenas atenuado na margem anterior; antenômeros $\mathrm{V}$-X fortemente expandidos desde a base com aspecto quadrangular; mesofêmures com espinho desenvolvido. Pelo padrão de colorido, conformação do protórax e das antenas, assemelha-se a Assycuera waterhousei (White, 1855), que também ocorre no norte do Brasil e da qual também não se conhece o macho. Nesta espécie, entretanto, os fêmures são lineares, deprimidos; o protórax é mais 
longo que metade do comprimento dos élitros, sendo destituído de estrias transversais; as antenas atingem apenas a base dos élitros e os mesofêmures são destituídos de espinho (NAPP \& MONNÉ 2001).

O nome da espécie homenageia o Dr. Sérgio Fragoso (MNRJ-EMBRAPA) pela sua contribuição ao conhecimento dos Cerambycidae.

\section{Ancylocera bruchi Viana, 1971}

Figs 3,13

Ancylocera bruchi Viana, 1971: 162, pl. 1, figs 4-6; Monné, 1994: 18; Monné \& Giesbert, 1995: 141; Gonzalez \& Di Iorio, 1997: 173.

VIANA (1971) descreveu minuciosamente e ilustrou ambos os sexos e o pronoto do macho de Ancylocera bruchi, espécie registrada apenas para Santiago del Estero, Argentina (MonNÉ 1994; MonNÉ \& GIESBERT 1995). São fornecidos novos registros para Córdoba e Tucumán. GoNZALEZ \& DI IORIO (1997) citaram como planta hospedeira Celtis pallida pallida Torrey (Ulmaceae).

Ancylocera bruchi e A. nigella (Figs 4, 12) são as únicas em que o protórax dos machos apresenta pontuação sexual densa em todo o protórax entremeada com pontos rasos e esparsos. As duas espécies distinguem-se prontamente pelo colorido e pela pontuação elitral, grossa e alinhada em A. nigella e fina, não alinhada em A. bruchi.

Material examinado. Argentina, Santiago del Estero: Rio Salado, 4 machos, 3 fềmeas, Wagner leg. (MNRJ); Córdoba: Córdoba, 1 fềmea, X.1947 (MNRJ); Tucumán: 1 macho (MNRJ).

\section{Ancylocera nigella Gounelle, 1913}

Figs 4, 12

Ancylocera nigella Gounelle, 1913; Monné, 1994: 18; Monné \& Giesbert, 1995: 141.

Após a descrição original, esta espécie só foi referida em catálogos (VIANA 1971; MONNÉ 1994). A descrição de GounELLE (1913) fornece elementos suficientes para o reconhecimento da espécie que se distingue das demais, principalmente pelos caracteres fornecidos na chave. GounELLE (1913) menciona que os mesofêmures apresentam espinhos no ápice interno e que, na fêmea, o pronoto é evidentemente estriado. No único macho examinado no presente estudo, a faixa sutural enegrecida é pouco aparente, o que sugere uma variabilidade deste caráter. Ancylocera nigella, até o momento, era conhecida apenas da localidade-tipo: La Garita, Colômbia. Um novo reg istro para o Panamá é fornecido.

Material examinado. PANAMÁ, Bajo Colorado: 1 macho, V.1942 (MNRJ).

\section{Ancylocera spinula sp. $\mathrm{n}$.}

\section{Fig. 2}

Fêmea. Colorido geral alaranjado; cabeça, quarto basal e margem posterior do pronoto pretos; antenas, pernas e esternos torácicos castanho-avermelhados. Dorso da cabeça com pontos microesculturados e confluentes. Genas com superfície microesculturada e pontos esparsos e rasos. Antenas apenas ultrapassam o terço basal dos 

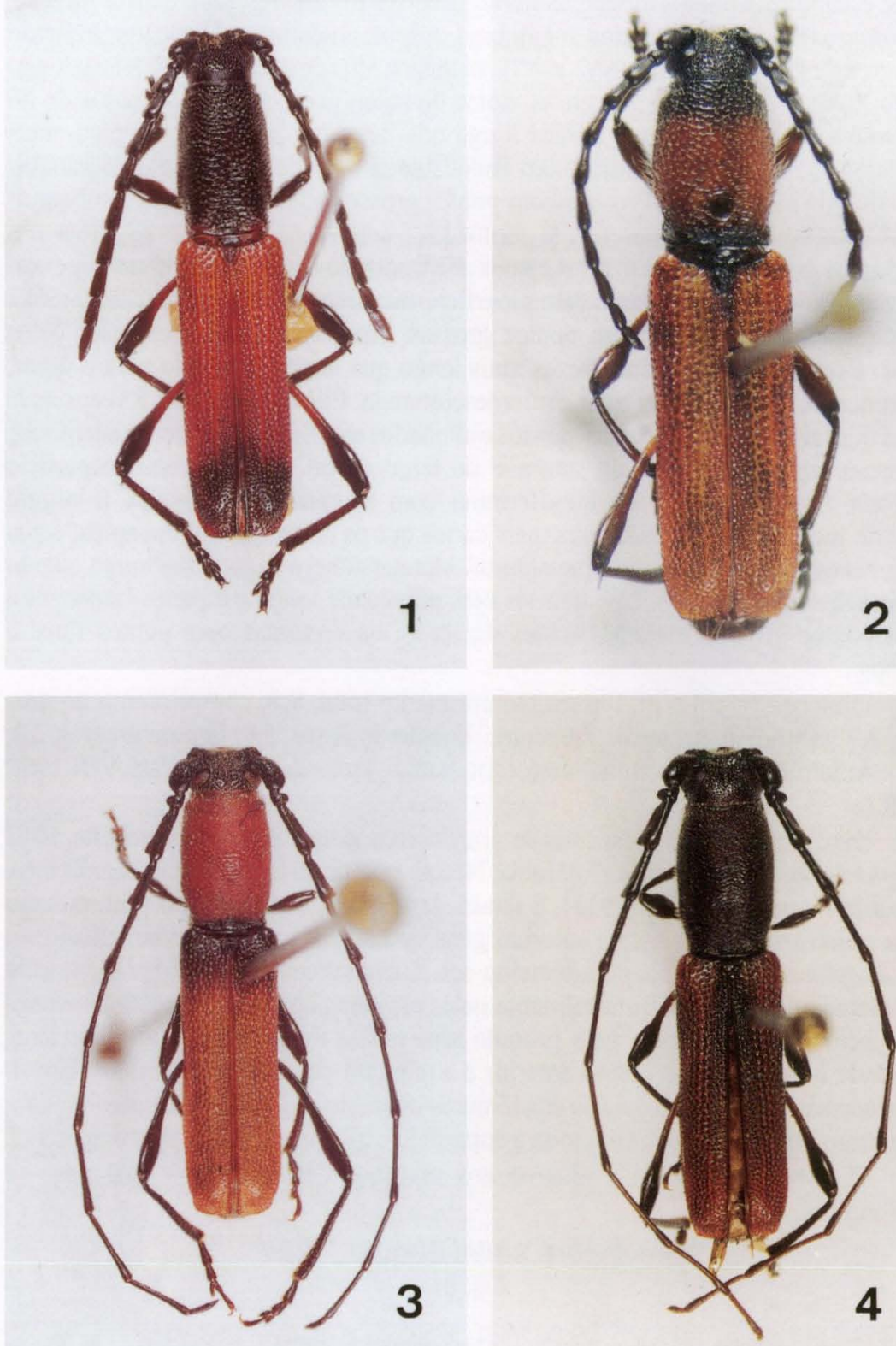

Figs 1-4. (1) Ancylocera sergioi sp. n., holótipo fêmea; (2) A. spinola sp. n., holótipo fêmea; (3) A. bruchi, macho; (4) A. nigella, macho. 
élitros; escapo com pontos moderadamente grossos e irregulares, mais densos na base; antenômeros III-XI impontuados, subglabros, opacos; antenômero III tão longo quanto IV e cerca de $1 / 3$ mais curto que V; V-VII subiguais; VIII-X decrescentes; XI tão longo quanto X; sistema porífero ausente no dorso do antenômero III e muito reduzido no IV. Protórax cerca de um terço mais longo que largo, os lados subparalelos, mais atenuados na margem posterior, e com abundante pilosidade longa, ereta, esbranquiçada em toda a superfície. Pronoto com pontos grossos, algo transversos e subcontíguos. Lados do protórax densamente pontuados e com estrias transversais. Prosterno com pontos grossos, bem marcados e mais adensados no disco. Mesosterno impontuado. Mesepimero e mesepisterno com superfície microesculturada e pubescência curta, esbranquiçada. Metasterno com pontos grossos, esparsos e rasos e esparsos pêlos longos. Escutelo cerca de duas vezes mais longo que largo, estreitado para o ápice, este truncado; superfície irregular e microesculturada. Élitros cerca de 2,5 vezes mais longos que largos; pontos grossos, densos e alinhados em fileiras; menores e adensados na metade apical ao longo da sutura e no terço apical. Fêmures com superfície subopaca. Espinho apical dos mesofềmures com comprimento subigual à largura apical do mesofềmur. Metafêmures mais curtos que os élitros, o espinho apical cerca de 1,5 vezes a largura apical do metafêmur. Metatarsômero I quase tão longo quanto os dois seguintes reunidos. Urosternitos com pilosidade longa e esparsa. Urosternito I com pontos grossos mais adensados no disco, os seguintes com pontos finos e esparsos.

Dimensões, em mm, fêmea. Comprimento total, 9,8; comprimento do protórax, 2,7; largura do protórax, 2,0; comprimento do élitro, 5,8; largura umeral, 2,2. (MNRJ).

Material-tipo. Holótipo fêmea, ColôMBIA, Valle del Cauca: Cali, VIII.1972

Discussão. Dentre as espécies de Ancylocera, apenas A. nigella Gounelle, 1913 e $A$. spinula sp. n., ocorrem na Colômbia. Não se examinou fềmeas de $A$. nigella mas, de acordo com GOUNELLE (1913), a fêmea desta espécie apresenta o pronoto com estrias transversais distintas e o colorido geral do corpo é castanho-avermelhado escuro. Ancylocera spinula sp. n., assemelha-se a A. michelbacheri (Fig. 6) pelo colorido geral alaranjado e difere, principalmente pelos espinhos apicais dos meso- e metafêmures bem desenvolvidos e pelo pronoto sem estrias transversais, com abundante pilosidade longa e com o quarto anterior e a margem posterior enegrecidos. Em $A$. michelbacheri os espinhos apicais dos fềmures são curtos e o pronoto é unicolor, com estrias transversais evidentes em toda a superfície e pilosidade curta, pouco aparente.

O nome da espécie é alusivo aos espinhos desenvolvidos dos meso- e metafêmures.

\section{Ancylocera sallei Buquet, 1857 Fig. 8}

Ancylocera sallei Buquet, 1857: 332; Monné, 1994: 19; Monné \& Giesbert, 1995: 141. Ancylocera sallaei [sic]; Noguera \& Chemsak, 1996: 402.

Macho. Tegumento de maneira geral acastanhado; estreita faixa mediana longitudinal do pronoto, lados do protórax, élitros, exceto ao longo da sutura, e pedúnculo dos fêmures vermelhos. Dorso da cabeça com pontuação moderadamente densa. Genas com pontos finos e esparsos. Antenas com superfície brilhan- 

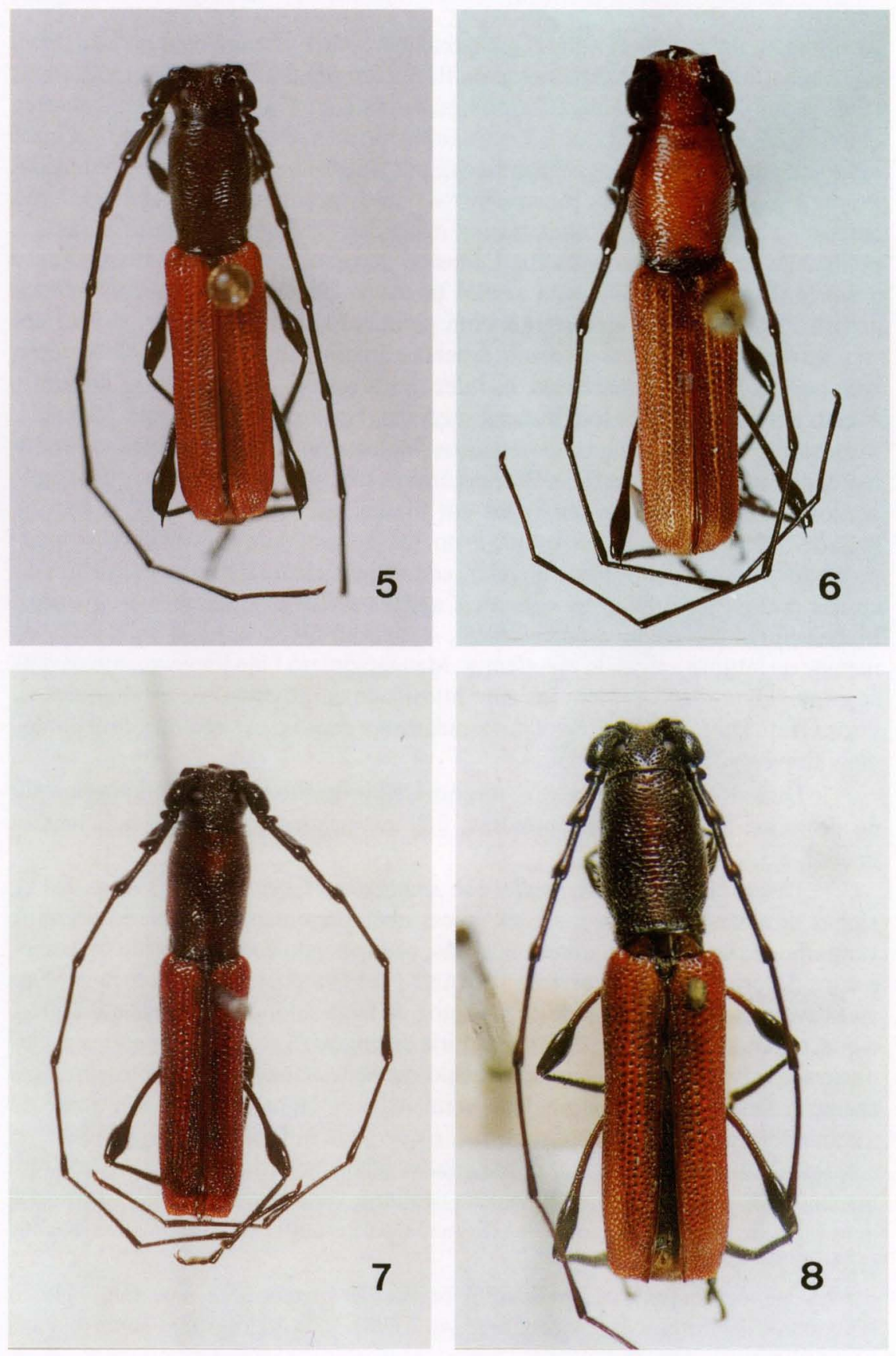

Figs 5-8. (5) Ancylocera bicolor, macho; (6) A. michelbacheri, holótipo macho; (7) A. amplicornis, holótipo macho; (8) A. sallei, macho. 
te, ultrapassam os ápices elitrais no antenômero VIII. Escapo com pontos finos, mais adensados na base. Antenômeros III-V com pontos finos, rasos e esparsos; III-IV com depressões medianas, subiguais em comprimento e $1 / 3$ mais curtos que o V; VII-IX subiguais; X 1/3 mais curto que o IX. Protórax cerca de 1/3 mais longo que largo, com lados subparalelos e pilosidade curta, ereta e esbranquiçada. Pronoto plano, com rugas transversais e pontos grossos, bem aparentes; terço anterior e posterior com rugas menos marcadas, os pontos menores e rasos e pontuação sexual pouco aparente. Lados do protórax com pontos grossos, rasos e subconfluentes, a pontuação sexual pouco aparente. Prosterno com pontos grossos, marcados, os interstícios com pontuação sexual aparente, exceto em estreita faixa longitudinal mediana, esparsa e grossamente pontuada. Mesosterno com pontos grossos e marcados, os interstícios com pontuação sexual aparente, exceto em estreita faixa longitudinal mediana, esparsa e grossamente pontuada. Mesosterno com pontos grossos e densos. Metasterno com pontos grossos e bem marcados em toda a superfície. Élitros cerca de três vezes mais longos que largos; pontos grossos, densos e alinhados em fileiras em toda superfície, exceto na metade apical ao longo da sutura e no $1 / 3$ apical onde são menores e mais próximos entre si. Escutelo triangular, com superfície quase lisa e com algumas cerdas curtas. Mesofêmures com abas apicais internas ligeiramente aguçadas. Metafêmures alcançam o ápice elitral, o espinho apical interno com cerca da metade da largura apical do metafêmur. Metatarsômero I tão longo quanto os dois seguintes reunidos. Urosternitos com pilosidade curta, esparsa e esbranquiçada. Urosternito I com pontos finos e moderadamente densos; os seguintes com pontos mais finos e adensados aos lados.

Dimensões, em milímetros, macho. Comprimento total, 11,2; comprimento do protórax, 3,3; largura do protórax, 2,2; comprimento do élitro, 6,5; largura umeral, 2,3 .

Discussão. Ancylocera sallei e A. amplicornis Chemsak, 1963 (Figs 7, 11), ambas descritas do México, são as únicas que apresentam os lados do protórax vermelho-alaranjados em grande extensão, contrastando com o colorido castanhoescuro do pronoto e do prosterno. BUQUET (1857) menciona a presença de duas áreas avermelhadas a cada lado do pronoto e de faixa sutural enegrecida nos élitros, o que, segundo CHEMSAK (1963) permitiria distinguir $A$. sallei das demais espécies mexicanas. Entretanto, no exemplar estudado neste trabalho, o pronoto apresenta apenas a faixa mediana longitudinal vermelha e os lados da sutura são quase do mesmo colorido do restante dos élitros, o que pode indicar uma variabilidade no colorido de $A$. sallei. A escassez de material estudado ( 1 macho de $A$. sallei e holótipo macho de $A$. amplicornis), não permite avaliar a variabilidade nos caracteres das duas espécies que se distinguem, basicamente, pela escultura do pronoto dos machos (vide chave, p. 5).

Até o momento A. sallei está registrada apenas para Yucatán, México (CHEMSAK 1963; Noguera \& CHEMSAK 1996). Não há registros sobre plantas hospedeiras.

Material examinado. 1 macho, ex. Col. H.W. Bates (MNHN). O holótipo não foi localizado. 


\section{Ancylocera amplicornis Chemsak, 1963}

Figs 7,11

Ancylocera amplicornis Chemsak, 1963: 107; Monné, 1994: 17; Monné \& Giesbert, 1995: 141; Noguera \& Chemsak, 1996: 402.

CHEMSAK (1963) considerou A. amplicornis semelhante a A. michelbacheri (Figs $6,9,10$ ), diferindo desta pela coloração escura da cabeça e do pronoto e também pela escultura do pronoto dos machos. Ressalte-se que CHEMSAK (1963) examinou apenas uma fêmea de $A$. sallei, aqui considerada como mais semelhante a A. amplicornis, cuja fêmea é desconhecida (vide comentários em A. sallei). Ancylocera amplicornis distribui-se do México a Honduras (MONNÉ, 1994; MONNÉ \& GIESBERT 1995) e não há registro de planta hospedeira.

Material examinado. MÉxICO, Chiapas: Cintalapa, holótipo macho, 06.IX.1962, F.D. Parker leg. (CASC).

\section{Ancylocera bicolor (Olivier, 1795)}

Fig. 5

Saperda bicolor Olivier, 1795: (68) 32, pl. 3, fig. 25.

Ancylocera bicolor; Audinet-Serville, 1834: 108; Monné, 1994: 17; Monné \& Giesbert, 1995: 141; Yanega, 1996: 125, pl. 19, fig. 227; Linsley \& Chemsak, 1997: 340-341.

Única espécie do gênero com distribuição restrita ao sudeste dos Estados Unidos, da Carolina do Norte e Flórida ao sul do Texas (LinsLeY 1964; MonNÉ 1994; MONNÉ \& GIESBERT 1995). A espécie foi redescrita por LINSLEY (1964) e figurada por YANEGA (1996). LINSLEY \& CHEMSAK (1997) arrolaram oito plantas hospedeiras para esta espécie: Acacia farnesiana (Linnaeus) Willdenow, Leucaena pulverulenta (Schlechtendal) Bentham, Prosopis glandulosa Torrey (Mimosaceae), Baccharis neglecta Nuttall (Asteraceae), Carya sp. (Juglandaceae), Celtis pallida Torrey, Ulmus crassifolia Nuttall (Ulmaceae), Quercus sp. (Fagaceae).

Material examinado. Estados Unidos, Flórida: Gainesville, 1 fêmea, XI. 1917, 2 fêmeas, IV.1922, G.O. Wiley leg., 2 machos, IX.1968, 1 macho, X.1968, 1 macho, X.1970, 1 macho, VII.1976 (MNRJ); Texas: 12 ms. w. of Boca Chica, 1 fêmea, 13.VIII.1955 (MNRJ).

\section{Ancylocera michelbacheri Chemsak, 1963}

Figs $6,9,10$

Ancylocera michelbacheri Chemsak, 1963: 108; Monné, 1994: 18; Monné \& Giesbert, 1995: 141; Chemsak \& Noguera, 1995: 63; Noguera \& Chemsak, 1996: 402.

Até o momento, com distribuição restrita ao México (Jalisco, Morelos, Oaxaca) (Noguera \& CHEMSAK 1996) e sem registro de planta hospedeira. O colorido geral do corpo varia entre alaranjado e vermelho. Diferencia-se de $A$. amplicornis (Figs 7, 11) e de A. sallei (Fig. 8), também descritas do México, pelo colorido uniforme do corpo, alaranjado a vermelho-alaranjado, o prosterno com ampla área, bem delimitada, enegrecida (Fig. 10) e pela escultura do protórax dos machos (vide chave). 
Material examinado. MÉXICO, Jalisco: Ajijic, holótipo macho, 5.VII.1962, A.E. Michelbacher leg. (CASC); Guadalajara, 1 macho, 1903, L. Diguet leg. (MNHN); Salatitlan (Arroyo Seco), 1 fêmea, VII.1953, C. \& P. Vaurieleg. (MZSP).
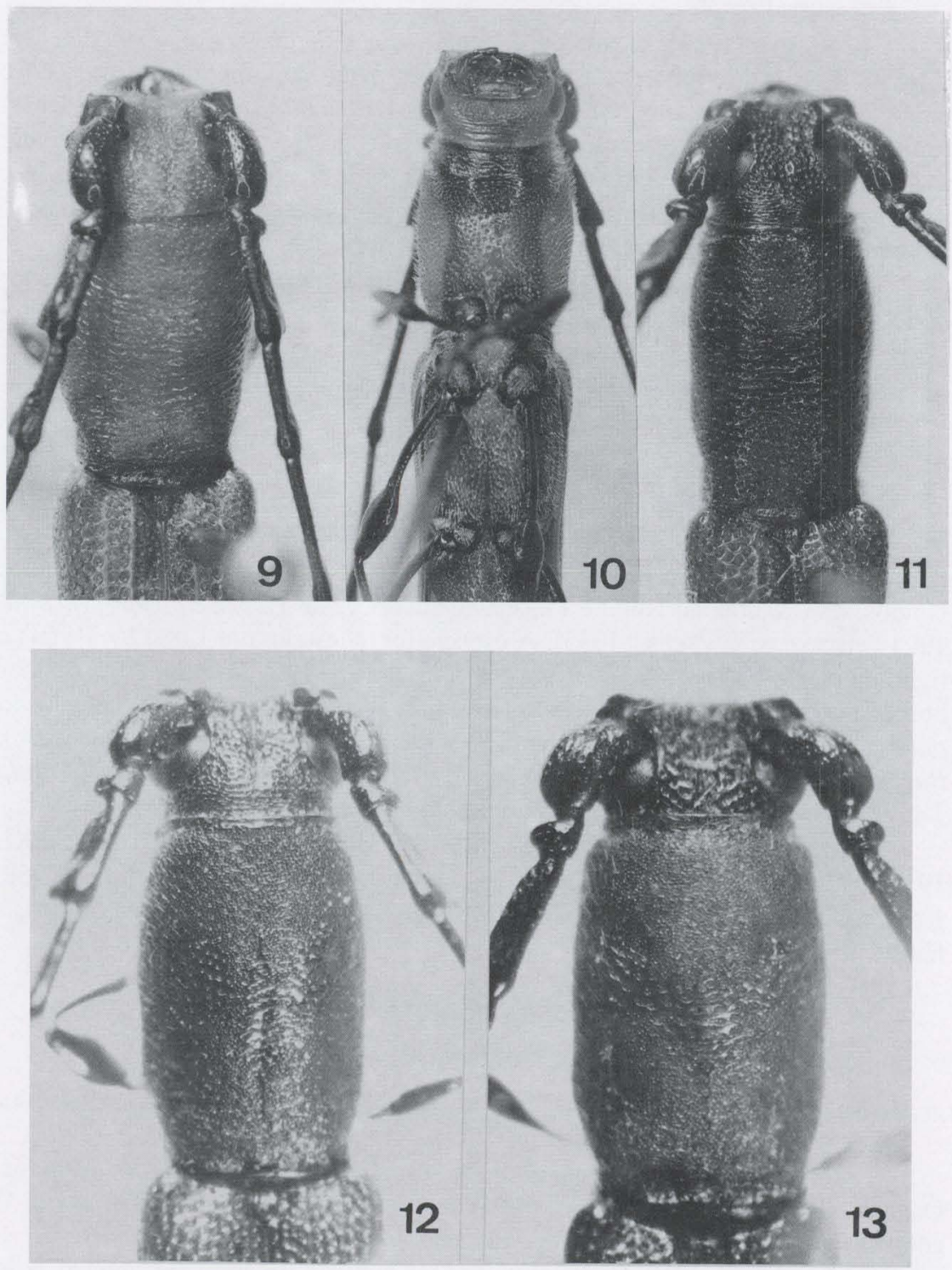

Figs 9-13. Protórax, macho. (9-10) Ancylocera michelbacheri, holótipo; A. michelbacheri, holótipo, prosterno; (11) A. amplicornis, holótipo; (12) A. nigella; (13) A. bruchi. 


\section{Ancylocera cardinalis (Dalman, 1823)}

Cerambyx ? cardinalis Dalman, 1823: 67.

Ancylocera cardinalis; Audinet-Serville, 1834: 108; Monné, 1994: 18; Monné \& Giesbert, 1995: 141; Di lorio \& Zelich, 1997: 277; Monné \& Napp, 2000a: 106-107, 128, figs 54, 55; Monné \& Napp, 2000b: 354, fig. 6 .

VIANA (1971) redescreveu minuciosamente esta espécie e forneceu ilustrações de ambos os sexos e do pronoto do macho. A. cardinalis é bastante comum e, talvez, a espécie mais conhecida do gênero, sendo referida por inúmeros autores (MONNÉ 1994). Apresenta ampla distribuição na região meridional da América do Sul e no Brasil está, aparentemente, relacionada à Floresta Atlântica. Pelos dados da literatura, as plantas hospedeiras de A. cardinalis são: Jacaranda cuspidifolia Martius (Bignoniaceae), Acacia bonariensis Gillies, A decurrens Willdenow (Mimosaceae), Scutia buxifolia Reisseck (Rhamanaceae) e Citrus aurantium Linnaeus (Rutaceae) (VIANA 1971; DI IORIO \& ZELICH 1997).

Ancylocera cardinalis caracteriza-se principalmente pela coloração geral vermelho-sanguinea que permanece constante apesar da ampla distribuição. Variações observadas referem-se à conformação do protórax das fêmeas, de cilíndrico a subarredondado aos lados; à escultura do pronoto com estrias transversais mais, ou menos evidentes; e às antenas dos machos, desde mais longas até mais curtas que o corpo, neste caso assemelhando-se às antenas das fêmeas mas mantendo o antenômero XI reduzido e em forma de gancho. Esta variabilidade nas antenas dos machos já foi reportada em outros gêneros de Ancylocerina (MONNÉ \& NAPP 2000a,b; NAPP \& MONNÉ 2001). Além disso, em alguns exemplares observou-se pequena faixa longitudinal enegrecida na metade basal do prosterno. MonNÉ \& NAPP (2000a) discutiram comparativamente a terminália feminina e masculina e ilustraram o oitavo esternito do macho e o tégmen.

Material examinado. BRAsIL, Mato Grosso: Dourados, l'macho, XII.1975, J. Lorenzoni leg.; Espírito Santo: Linhares, 1 fêmea, X.1966, A. Maller leg.; 1 macho, 1 fêmea, 20.IX.1972, C. Elias leg.; 1 macho, 1 fềmea, 5.X.1972, C. Elias leg.; 1 macho, 1 fêmea, 6.XI.1972, C. Elias leg.; 1 macho, 1 fềmea, 21.XII.1972, C. Elias leg.; Santa Tereza, 2 fềmeas, XI.1964, C. Elias leg.; 2 fềmeas, 20.X.1966, C.T. \& C. Elias leg.; Rio de Janeiro: Corcovado, 1 macho, 3.XII.1965, Moure \& Seabra leg.; Paraná: Piraquara, 1 fêmea, 13.I.1968, Moure \& Laroca leg.; 1 fêmea, 15.XII.1969, F. Giacomel leg.; Curitiba, 1 macho, 2 fêmeas, 10.X.1977, F. Giacomel leg.; Ponta Grossa, 1 macho, 1 fêmea, XII.1943, ex-col. Justus; Santa Catarina: São Francisco do Sul, 2 machos, I.1971, A. Maller leg. (DZUP).

AGRADECIMENTOS. A D. Kavanaugh (CASC) pelo empréstimo dos tipos de A. amplicornis e A. michelbacheri; a M. A. Monné (MNRJ) e U.R. Martins (MZSP) pelo empréstimo de material e a A.M. Sakakibara (DZUP) pela confecção das fotografias.

\section{REFERÊNCIAS BIBLIOGRÁFICAS}

Audinet-Serville, J.G. 1834. Nouvelle classification de la famille des longicornes (suite). Ann. Soc.

Ent. France (1) 3: 5-110.

BUQUET, J.B. 1857. Description d'une nouvelle espèce de longicorne du genre Ancylocera. Archiv. ent.

1: $332-333$.

Revta bras. Zool. 18 (3): 989 - 1002, 2001 
CHEmSAK, J.A. 1963. Synopsis of the genus Ancylocera in Mexico (Coleoptera, Cerambycidae). Jour. Kansas ent. Soc. 36 (2): 104-109.

Chemsak, J.A. \& F.A. Noguera. 1995. Annotated checklist of the Cerambycidae of the Estacion de Biologia Chamela, Jalisco, Mexico (Coleoptera), with descriptions of a new genera and species. Folia Ent. Mex. 89: 55-102.

Dalman, J.W. 1823. Analecta entomologica. Holmiae, VIII+108p.

DI IoRIO, O.R. \& M. ZeLICH. 1997. Cerambycidae (Coleoptera) from Entre Ríos, Argentina. Part I. Host plants and distributions (with a revision of host plants for Uruguay). G. it. Ent. 8 (46): 275-289.

GonZalez O.E. \& O.R. DI IORIO. 1997. Plantas hospedadoras de Cerambycidae (Coleoptera) en el noroeste de Argentina. Revta Biol. Trop. 44/45 (3-1): 167-175.

Gounelle, E. 1913. Cérambycides nouveaux de Colombie, appartenant au Musée de Hambourg (Col.). Bull. Soc. Ent. France 1913: 419-423.

Linsley, E.G. 1964. The Cerambycidae of North America. Part V. Taxonomy and classification of the subfamily Cerambycinae, tribes Callichromini through Ancylocerini. Univ. Calif. Publs Ent. 22: 1-197.

Linsley, E.G. \& J.A. Chemsak. 1997. The Cerambycidae of North america, Part VIII: Bibliography, Index and Host Plant Index. Univ. Calif. Publs Ent. 117: 1-534.

MonNé, M.A. 1994. Catalogue of the Cerambycidae (Coleoptera) of the Western Hemisphere. Part XI. São Paulo, Soc. Bras. Ent., 157p.

MONNÉ, M.A. \& E.F. GIESBERT. 1995. Checklist of the Cerambycidae and Disteniidae (Coleoptera) of the Western Hemisphere. Burbank, Wolfsgarden Books, XIII+419p.

MonNÉ, M.L. \& D.S. NAPP. 2000a. Revisão do gênero Ceralocyna (Coleoptera, Cerambycidae, Trachyderini, Ancylocerina). Iheringia, Sér. Zool., Porto Alegre, (88): 103-137.

- 2000b. Two new South American genera of Ancylocerina (Cerambycidae, Cerambycinae, Trachyderini). Coleopts Bull. 54 (3): 351-358.

NAPP, D.S. \& M.L. MonNE. 2001. Assycuera, a new Neotropical genus of Ancylocerina (Coleoptera, Cerambycidae, Trachyderini). Revta bras. Zool 18 (3): 977-987.

Noguera, F.A. \& J.A. Chemsak. 1996. Cerambycidae (Coleoptera), p. 381-409. In: J.L. Bousquets; A.N.G. Aldrete \& E.G. Soriano (Eds). Biodiversidad, Taxonomia y Biogeografia de Artrópodos de México: Hacia una síntesis de su conocimiento. México, Univ. Nacional Autónoma México, 660p.

OLIVIER, A.G. 1795. Entomologie, ou histoire naturelle des insectes. Coléoptères. Paris, Desray, Vol. 4, p. $1-519$.

THOMSON, J. 1864. Systema cerambycidarum ou exposé de tous les genres compris dans la famille des cérambycides et familles limitrophes. Mém. Soc. r. Sci. Liège 19: 1-540.

VIANA, M.J. 1971. Las espécies argentinas de Ancylocerini Thomson y catálogo bibliográfico de la tribu (Coleopt., Cerambycidae, Cerambycinae). Revta Mus. Arg. Ci. Nat. Bernardino Rivadavia, Entomol., 3 (3): 149-205.

YANEGA, D. 1996. Field Guide to Northeasten Longhorned beetles (Coleoptera, Cerambycidae). Illinois Nat. Hist. Surv. 6: 1-174.

Recebido em 15.XII.2000; aceito em 28.VIII.2001 